\title{
Usage, Risk, and Benefit of Weight-Loss Drugs in Primary Care
}

\author{
Tomas Forslund, ${ }^{1}$ Pauline Raaschou, ${ }^{2}$ Paul Hjemdahl, ${ }^{2}$ \\ Ingvar Krakau, ${ }^{3}$ and Björn Wettermark ${ }^{4}$ \\ ${ }^{1}$ Gröndal Primary Care Centre, P. O. Box 470 43, 10074 Stockholm, Sweden \\ ${ }^{2}$ Department of Clinical Pharmacology, Karolinska University Hospital, Solna, 14186 Stockholm, Sweden \\ ${ }^{3}$ Centre for Family and Community Medicine, Karolinska Institutet and Stockholm County Council, Huddinge, Sweden \\ ${ }^{4}$ Drug Management and Informatics, 11827 Stockholm, Sweden \\ Correspondence should be addressed to Tomas Forslund, tomas.forslund@sll.se
}

Received 31 December 2010; Accepted 12 April 2011

Academic Editor: Eliot Brinton

Copyright (๑) 2011 Tomas Forslund et al. This is an open access article distributed under the Creative Commons Attribution License, which permits unrestricted use, distribution, and reproduction in any medium, provided the original work is properly cited.

Purpose. To investigate the use of the weight-loss drugs rimonabant, sibutramine, and orlistat in primary care and to characterize the patients receiving the drugs. Methods. In this retrospective, descriptive study, 300 randomly selected patients having started weight-loss drug treatment at 15 primary care centres were investigated using the patient's medical records and their complete drug purchase data. Results. Even though $48 \%$ of the patients specifically demanded drug treatment, $77 \%$ continued treatment less than one year. $28 \%$ of rimonabant patients and $32 \%$ of sibutramine patients had a history of depression or antidepressant treatment. $41 \%$ of sibutramine patients had a history of hypertension and/or cardiovascular disease. $36 \%$ had no documented weight after treatment initiation. Conclusions. These results suggest that weight-loss drug treatment was often initiated upon patient request but was of limited clinical benefit as it was managed in a large portion of Swedish primary carecenters.

\section{Introduction}

Obesity is a prevalent chronic condition which is associated with significant morbidity and mortality [1]. The prevalence is increasing rapidly in all countries, with WHO estimating 1.6 billion overweight adults and 400 million obese adults in 2005 [2]. Although not being one of the worst inflicted countries, the prevalence of obesity in Sweden has also increased substantially over the last decades, and it has been estimated that $10 \%$ of both men and women are obese, and a further $40 \%$ are overweight [3]. Consequently, there is an urgent need for effective life-style interventions and often also pharmacological treatment.

The development of antiobesity medicines has been problematic and characterized by heavy marketing followed by withdrawals from the market after reports of safety problems, including pulmonary hypertension (aminorex), valvular lesions (dexfenfluramine-phentermine), and addiction (amphetamine) [4]. This pattern has continued in recent years with the withdrawal of rimonabant (Acomplia) in
October 2008 and sibutramine (Reductil, Reduxade, Zelium) in January 2010 due to safety concerns $[5,6]$. Currently, orlistat is the only registered weight-loss drug on the European market, but new drugs are in the pipeline $[7,8]$.

In the metropolitan health region of Stockholm, Sweden, a model has been developed which includes horizon scanning (to prepare for drugs to come), forecasting of drug utilization and expenditures, critical drug evaluation, and structured programs for the introduction and followup of new drugs [9]. When rimonabant was given the marketing approval in 2006, the subsequent marketing activities led to concerns about improper use and inappropriate increase in expenditure. Rimonabant was, therefore, one of the drugs selected for a structured introduction and followup program. In 2006, the total expenditure for weight-loss drugs was 154 million SEK in Sweden [10].

This study is a characterization of the use of weightloss drugs in the primary health care setting of Stockholm County. The aim was to analyse the utilization and effectiveness of the three weight-loss drugs rimonabant, sibutramine, 
TABLE 1: The three weight-loss drugs on the Swedish market in 2008.

\section{Rimonabant}

Rimonabant (Acomplia) is a cannabinoid CB1-receptor earlierly registered in Europe for the treatment of overweight with risk factors (BMI over 27 with dyslipidemia or diabetes) or obesity (BMI over 30) in combination with lifestyle interventions. In Sweden, the drug was reimbursed only if BMI was over 28 with dyslipidemia or diabetes, or if BMI was over 35 [11]. A meta-analysis has shown a placebo-adjusted weight loss of $4.3 \mathrm{~kg}$ after one year of treatment [12]. Contraindications included ongoing depression or treatment with antidepressant drugs [11]. Rimonabant was withdrawn from the market in October 2008 due to the risk of psychiatric side effects [5].

Orlistat

Orlistat (Xenical) is a gastrointestinal lipase inhibitor registered in Europe and the US for the treatment of overweight with risk factors (BMI over 27 with dyslipidemia or diabetes) or obesity (BMI over 30) in combination with diet interventions. In Sweden, the drug is reimbursed only if BMI is over 28 with dyslipidemia or diabetes, or if BMI is over 35 [13]. A meta-analysis has shown a placebo-adjusted weight loss of $2.7 \mathrm{~kg}$ after one year of treatment [12]. Malabsorption is a contraindication [13].

Sibutramine
Sibutramine (Reductil) is a serotonin, norepinephrine, and
dopamine reuptake inhibitor earlierly registered in Europe for
the treatment of overweight with risk factors (BMI over 27 with
dyslipidemia or diabetes) or obesity (BMI over 30) in
combination with lifestyle interventions. In Sweden, the drug was
reimbursed only if BMI was over 28 with dyslipidemia or
diabetes, or if BMI was over 35 [14]. A meta-analysis has shown a
placebo-adjusted weight loss of 4.3 kg after one year of treatment
[12]. Contraindications were among others cardiovascular
disease, psychiatric disease, ongoing treatment with
antidepressant or antipsychotic drugs, and uncontrolled
hypertension [14]. Sibutramine was withdrawn from the market
in January 2010 due to an increased risk of cardiovascular
incidents [6].

and orlistat (see Table 1) which were on the Swedish market in 2008. Rimonabant was withdrawn from the market toward the end of the study period, which limits the possibility of conducting a 1-year evaluation for this drug. Sibutramine was withdrawn after the study period, while orlistat still remains on the market.

\section{Methods}

2.1. Medical Record Data. We conducted a retrospective, descriptive study based on data extracted from electronic medical records in primary healthcare. All data were extracted using Rave3 software (Medrave Software AB, Stockholm) $[15,16]$. The Rave3 software extracts data from the medical record database in a systematic way making it possible to link most of the recorded data such as diagnosis, laboratory findings, and text registered in the medical record. A validation was done confirming that the extracted data was in agreement with the medical records. Rave3 performed well regarding the extraction of data documented in association with a specified term, but an additional manual analysis had to be performed to include the missing medical data.

A total of 36 primary healthcare centres (PHCs) comprising the Southwest district of the Stockholm County Council were invited to participate in the study. 24 of them used electronic medical records adapted to the Rave3 software and were thus able to participate. Among them, 15 practices agreed to participate and were included in the study.

Specific parameters as well as unformatted medical record information from November 1, 2005 to February 28, 2009 were centrally extracted with Rave3, anonymised, and entered into a database for further analysis. Thus all patients could be evaluated during at least 15 months after the start of treatment. Data regarding diagnosis of depression, antidepressant treatment, or earlier treatment with orlistat or sibutramine were also extracted back to the year 2000 in order to obtain some important characteristics of the patients before November 1, 2005.

2.2. Prescription Data. To assess to what extent the patients redeemed their prescriptions, data from the medical records were linked to data on dispensed drugs in the Swedish Prescribed Drug register [17]. The National Board of Health and Welfare is responsible for keeping this register which contains data on all prescription drugs dispensed in Sweden from 2005 and onwards, their amounts and dosages, expenditures and reimbursement, as well as the age, the gender and the unique identifier (personal identification number) of the patient. Using anonymised record linkage, we analysed the dispensing histories for all of patients' prescriptions between November 1, 2005 and February 28, 2009 to assess all the drugs that the patients actually had purchased from the pharmacy, regardless of the origins of the prescriptions. It also permitted an analysis of the persistence of weight-loss treatment.

The terminology and methodology used for measuring persistence varies across studies [18]. We defined persistence as the total number of days on treatment measured by the amount of drugs purchased from the pharmacy divided by the usual number of dosages for the drug. The reason for our choice is that weight-loss drugs have not been indicated for long-term risk reduction but for a limited period of weightloss treatment. The duration of treatment is, thus, more important in this case than for chronic treatment where adherence is more interesting. Defined daily doses (DDD) were not used due to the availability of sibutramine in both 10-mg and 15-mg compositions, which would have overestimated the treatment duration of this drug.

2.3. Statistics. Standard descriptive statistics (numbers, proportions, median, interquartile range, and range) were used to describe the study cohort and the utilization patterns. Data are presented with $95 \%$ exact binomial confidence intervals (CI) for proportions, where appropriate.

2.4. Ethics. The study was approved by the regional ethics committee. 


\section{Results}

3.1. Population. The $15 \mathrm{PHCs}$ included were responsible for a total of 205, 440 patients in 2008. Rave3 identified a total of 876 patients who had commenced treatment with weightloss drugs at these primary care centres between November 1 , 2006 and November 30, 2007, that is, a period of 13 months. 370 patients $(42 \%)$ had received rimonabant, 230 patients (26\%) had received orlistat, and 276 patients had received sibutramine $(32 \%)$. The number of unique patients was 829 due to the fact that an individual patient could have started treatment with different weight-loss drugs during this time period. The present analysis was limited to 100 randomly chosen patients for each weight-loss drug, that is, 300 patients in total. The number of unique patients analysed was 294 .

3.2. Selection Bias. In order to detect possible selection bias, we characterized the participating PHCs and compared them to the nonincluded centres. The participating centres were more often publicly managed and had more patients than the nonparticipating centres. The proportion of older patients, the number of visits per patient, the average drug expenditure per patient, and the proportion of prescriptions for weight-loss drugs compared to the total amount of prescriptions were similar. The population-base living next to the centres was also similar, as evaluated by age spans, unemployment, beneficiaries of social aid, immigrants, as well as levels of education and proportions of low- and high-income households. Thus, the comparison revealed no potentially important differences between PHCs who participated in the study and those who did not (data not shown).

3.3. Diabetes and/or Dyslipidemia. Of the patients who initiated weight-loss drug treatment, $65 \%$ had a diagnosis of diabetes and/or dyslipidemia, treatment for such a diagnosis, or laboratory tests indicating such a condition (see Table 2). The incidence was evenly distributed among the three weight-loss drugs. $32 \%$ had treatment for diabetes and/or dyslipidemia.

3.4. Cardiovascular Disease. Cardiovascular disease or uncontrolled hypertension was contraindications for treatment with sibutramine. $41 \%$ of the patients who started treatment with sibutramine had at least one diagnosis or treatment consistent with hypertension and/or other cardiovascular disease (see Table 2). The first or last blood pressure during the study period was above $140 / 90 \mathrm{~mm} \mathrm{Hg}$ in another $7 \%$ of the patients.

3.5. Psychiatric Disease. Contraindications for rimonabant and sibutramine included ongoing depression or treatment with antidepressants. $28 \%$ of the patients who started treatment with rimonabant and $32 \%$ of the patients with sibutramine had a diagnosis of depression and/or antidepressant treatment during the study period (see Table 2). Whether the depression and/or antidepressant treatment was present before the initiation of weight-loss drug treatment, occurred during the treatment, or occurred after the treatment, has not been analysed. 58\% of rimonabant patients and 56\% of sibutramine patients had signs of psychiatric problems in their medical history (anxiety, sleeping disorder, stress disorders, professional burnout, eating disorder, or treatment for such conditions). Psychiatric disease was a contraindication for sibutramine. Patients treated with orlistat had a slightly higher frequency of both depression or treatment of depression and other psychiatric problems, but such patients can be treated with the drug without additional risk.

3.6. Initiative to Treat. In $48 \%$ of the cases, it was clearly stated in the medical file that the patient asked for treatment with weight-loss drugs, often with the wish for a specific drug. It was unclear whether the patient or the prescribing physician had taken the initiative to drug treatment in 50\% of the cases. In only $2 \%$ of the cases, it was clearly stated that the physician had proposed treatment with the weight-loss drug.

3.7. Prescription of Other Weight-loss Drugs. In total, $40 \%$ of the patients had tried one or both of the other weightloss drugs during the study period $-48 \%$ of those receiving rimonabant, $46 \%$ of those receiving sibutramine, and $27 \%$ of those receiving orlistat.

3.8. Weight Change. In $51 \%$ of all 300 patients, Rave3 found no documentation of the patient's weight under the right heading in the electronic medical record. We therefore also conducted a manual evaluation of the case records. We limited this analysis to patients having been prescribed the weight-loss drug for at least one year since a meaningful effect on weight requires a long period of treatment. Among the 300 manually analysed patient records, 100 patients had been prescribed the drug for one year or longer -48 had had rimonabant, 31 sibutramine, and 21 orlistat. These patients were further analysed regarding the last documented weight after at least 9 months of treatment. In 62 patients the data were insufficient to evaluate changes in weight. 28 patients had lost weight, and 10 patients had an unchanged weight.

Only 18 out of the 300 patients, that is, $6 \%$ had the drug prescribed for at least one year and a confirmed clinically relevant weight-loss of at least 5\% after at least 9 months of treatment (see Figure 1). Whether the weight loss achieved depended on the drug treatment or other factors cannot be concluded in this study, and possible long-term changes in weight among other patients could not be deduced from the medical records.

3.9. Documentation of Weight. $26 \%$ of the patients who had been prescribed the weight-loss drug for at least one year lacked documentation of his/her initial weight or weight within 3 months prior to the prescription. 36\% lacked a followup weight on any occasion after the initiation of treatment. For these reasons, it was impossible to draw any conclusions regarding treatment efficacy in $45 \%$ of the patients. This indicates that the management and followup of patients treated with weight-loss drugs was inadequate. 
TABle 2: Patient characteristics (Values within parentheses are 95\% Confidence Intervals (CI). CIs around medians calculated by binomial method, and around relative frequencies by exact binomial method.).

\begin{tabular}{|c|c|c|c|c|}
\hline & $\begin{array}{c}\text { All patients } \\
(N=300)\end{array}$ & $\begin{array}{c}\text { Rimonabant patients } \\
(N=100)\end{array}$ & $\begin{array}{l}\text { Sibutramine patients } \\
\qquad(N=100)\end{array}$ & $\begin{array}{c}\text { Orlistat patients } \\
(N=100) \\
\end{array}$ \\
\hline Median age & 47 & $55(50-57)$ & $42(40-45)$ & $49(45-53)$ \\
\hline $\mathrm{P}_{25}$ & 39 & 44 & 35 & 39 \\
\hline $\mathrm{P}_{75}$ & 59 & 63 & 54 & 59 \\
\hline Age span & $17-96$ & $23-78$ & $17-76$ & $21-96$ \\
\hline Men & $23 \%$ & $23 \%(15-32)$ & $18 \%(11-27)$ & $28 \%(19-38)$ \\
\hline Women & $77 \%$ & $77 \%(68-85)$ & $82 \%(73-89)$ & $72 \%(62-81)$ \\
\hline \multicolumn{5}{|l|}{ Body Mass Index } \\
\hline No BMI & $29 \%$ & $25 \%(17-35)$ & $31 \%(22-41)$ & $31 \%(22-41)$ \\
\hline $\mathrm{BMI}<28 \mathrm{~kg} / \mathrm{m}^{2}$ & $5 \%$ & $5 \%(2-11)$ & $3 \%(0.6-9)$ & $7 \%(3-14)$ \\
\hline BMI $28-35 \mathrm{~kg} / \mathrm{m}^{2}$ & $32 \%$ & $36 \%(27-46)$ & $27 \%(19-37)$ & $32 \%(23-47)$ \\
\hline $\mathrm{BMI}>35 \mathrm{~kg} / \mathrm{m}^{2}$ & $34 \%$ & $34 \%(25-44)$ & $39 \%(29-49)$ & $30 \%(21-40)$ \\
\hline \multicolumn{5}{|l|}{ Concomitant diseases and treatments } \\
\hline Diabetes & $24 \%$ & $31 \%(22-41)$ & $13 \%(7-21)$ & $28 \%(19-38)$ \\
\hline Dyslipidemia & $63 \%$ & $72 \%(62-81)$ & $60 \%(50-70)$ & $57 \%(47-67)$ \\
\hline Diabetes, and/or dyslipidemia & $65 \%$ & $75 \%(65-83)$ & $60 \%(50-70)$ & $61 \%(51-71)$ \\
\hline Treatment for diabetes & $19 \%$ & $26 \%(18-36)$ & $9 \%(4-16)$ & $22 \%(14-31)$ \\
\hline Treatment for dyslipidemia & $24 \%$ & $36 \%(27-46)$ & $15 \%(9-24)$ & $21 \%(13-30)$ \\
\hline $\begin{array}{l}\text { Treatment for diabetes and/or } \\
\text { dyslipidemia }\end{array}$ & $32 \%$ & $43 \%(33-53)$ & $21 \%(13-30)$ & $33 \%(24-43)$ \\
\hline $\begin{array}{l}\text { Cardiovascular disease and/or } \\
\text { hypertension }\end{array}$ & $51 \%$ & $66 \%(56-75)$ & $41 \%(31-51)$ & $47 \%(37-57)$ \\
\hline $\begin{array}{l}\text { Depression and/or antidepressant } \\
\text { treatment }\end{array}$ & $34 \%$ & $28 \%(19-38)$ & $32 \%(23-42)$ & $42 \%(32-52)$ \\
\hline Psychiatric problems & $60 \%$ & $58 \%(48-68)$ & $56 \%(46-66)$ & $66 \%(56-75)$ \\
\hline Pain and other musculoskeletal problems & $66 \%$ & $67 \%(57-76)$ & $65 \%(55-74)$ & $66 \%(56-75)$ \\
\hline
\end{tabular}

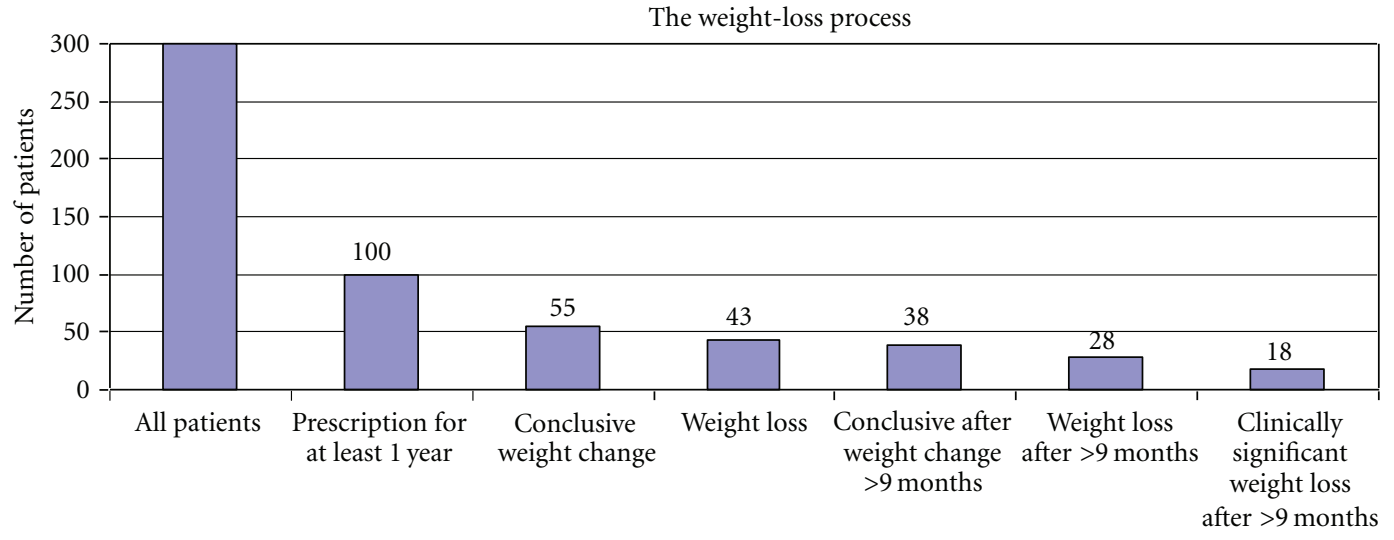

FIgURE 1: The weight loss process.

3.10. Treatment Persistence. Although 33\% of the 300 patients in the present study had been prescribed drug treatment for at least one year, it appears that $23 \%$ of them actually purchased the drugs for at least one year of treatment $-32 \%$ on rimonabant, $25 \%$ on sibutramine, and $13 \%$ on orlistat (see Figure 2). Among the 300 patients, 6\% never filled the first prescription at the pharmacy.
3.11. Treatment Discontinuation. Most commonly, no reason for discontinuation was documented ( $65 \%$ of the patients). The most common cause for discontinuation of rimonabant was prescription until, or past, the date of market withdrawal which is reported under "Other" (see Table 3). Other common reasons included side effects reported by $15 \%$ and dissatisfaction with the effect reported by $11 \%$. The 


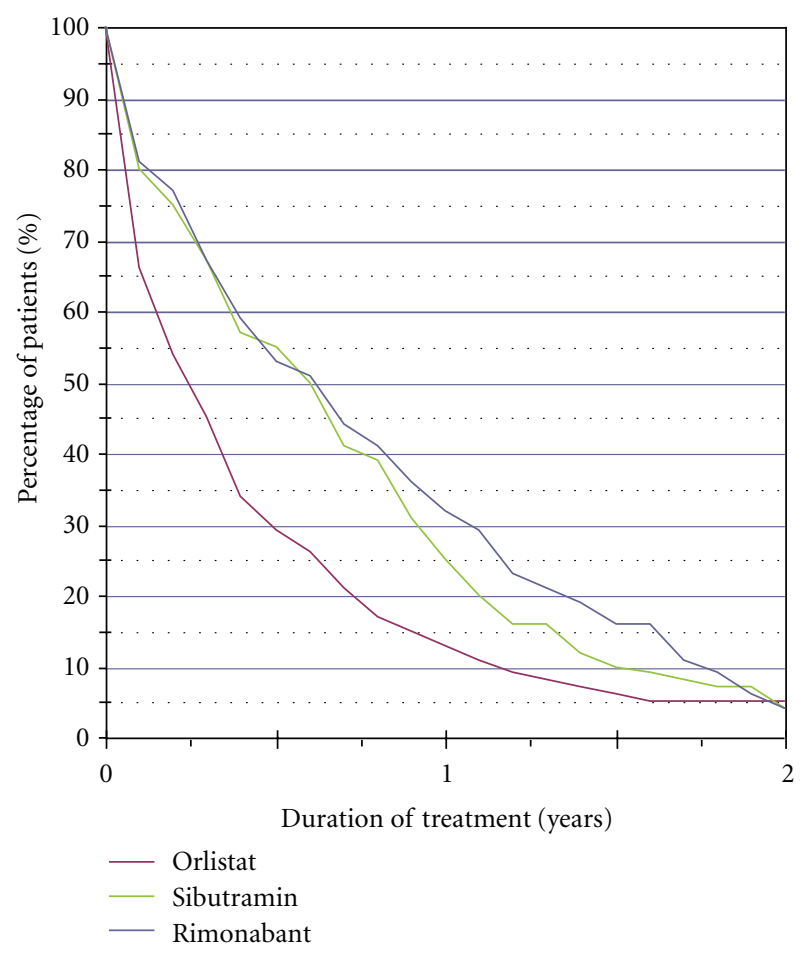

Figure 2: Percentage of patients left on treatment.

most commonly documented causes for discontinuation for patients having received sibutramine were dissatisfaction with the effectiveness of the drug and side effects reported by $11 \%$ each. $7 \%$ of the patients having received orlistat stopped treatment due to dissatisfaction with the effectiveness, and $4 \%$ quitted due to side effects.

\section{Discussion}

In this retrospective, descriptive study, prescription routines for 300 randomly selected patients having started weight-loss drug treatment at 15 primary care centres were investigated using patients' electronic medical records and their complete drug purchase data from the Swedish National Board of Welfare. Generally, patients who received weight-loss drugs had a poor health status with cardiovascular disease, diabetes, dyslipidemia, depression, and other psychiatric problems. Many had attempted treatment with other weight-loss drugs, and a significant proportion had listed contra-indications to the prescribed drug. Even though the patients often specifically demanded weight-loss drug treatment from the doctor, $77 \%$ continued treatment for less than one year. A large proportion of the patients were not weighed prior to treatment initiation and not followed within the context of a structured lifestyle intervention.

Prescription of weight-loss drugs was the most common in the Stockholm County Council than elsewhere in the country [10]. Our results are thus not generally applicable throughout Sweden but suggest problems that probably exist to varying degrees at many primary care centres. However, our earlier analysis of national prescription data for weight-loss drugs in Sweden showed similar results with a frequent history of use of other weight-loss drugs and antidepressant drugs, and with many patients who were not on drug treatment for diabetes and/or dyslipidemia [10]. Needless to say, the management of overweight patients might vary between different units and prescribers.

The present results suggest that many patients were prescribed weight-loss drugs despite possible or definite contraindications. It is remarkable that information about the key variable of interest, that is, body weight, was so often lacking in the medical records. All three weight loss drugs were only licensed for weight-loss treatment in combination with a structured weight loss program including exercise and diet. Regular followup including weight measurements both before and during such a program is essential and should be a mainstay in the treatment of overweight. The moderate weight loss seen in clinical trials of these drugs [12] is not generally applicable to short-term treatments without followup. Frequent prescriptions for patients with contraindications or other conditions prompting for caution are an important safety aspect. Both rimonabant and sibutramine have been withdrawn from the market. The present data support the wisdom of these withdrawals.

Even though advertising for prescription drugs is illegal in the European Union, it was often stated in the medical records that the reason for consulting the doctor was to obtain weight-loss drug treatment, often with the wish for a specific drug. Safety and efficacy concerns normally appear to have a major influence on the use of new drugs in primary care [19]. However, denying treatment to a patient who through media, friends, the Internet, or other sources has got the impression that there are effective drugs for losing weight is a delicate task and requires knowledge on the behalf of the prescriber in order to motivate his/her decision to treat or not to treat with a drug. Additional possibilities to advertise directly to patients would probably further increase the problems described in this article [20,21].

In our earlier analysis of the national prescription data, we found that only $1 / 3$ of the patients who started treatment with rimonabant during its first six weeks on the market continued the treatment after 6 months [10]. A Canadian evaluation of the treatment persistence with sibutramine and orlistat showed that less than $10 \%$ of the patients remained on treatment after one year, and less than $2 \%$ continued treatment after 2 years [22]. Maintaining the patients on treatment has been a problem also in the clinical trials [12, 23]. For example, the drop-out rate in the clinical trials of rimonabant was $35-50 \%$ during the first year [24-27]. Lack of persistence with treatment was a major problem in this study as well. Lack of efficacy or adverse events are the likely major causes of premature discontinuation of treatment. However, the reasons are seldom clearly stated in the medical record.

4.1. The Future. It is likely that the trend of informed patients actively seeking medical treatment for lifestylerelated conditions will increase. It might be problematic to achieve a rational use of drugs which are seldom prescribed 
TABLE 3: Reasons for discontinuation.

\begin{tabular}{|c|c|c|c|c|c|c|c|c|c|}
\hline & Unclear & $\begin{array}{c}\text { Not } \\
\text { terminated }\end{array}$ & Other & $\begin{array}{c}\text { Lack of } \\
\text { effect }\end{array}$ & $\begin{array}{l}\text { Neurological } \\
\text { side effects }\end{array}$ & $\begin{array}{l}\text { Psychiatric } \\
\text { side effects }\end{array}$ & $\begin{array}{l}\text { Gastrointestinal } \\
\text { side effects }\end{array}$ & $\begin{array}{l}\text { Cardiovascular } \\
\text { side effects }\end{array}$ & $\begin{array}{l}\text { Other side } \\
\text { effects }\end{array}$ \\
\hline $\begin{array}{l}\text { Rimonabant } \\
(N=100)\end{array}$ & $53 \%$ & $0 \%$ & $21 \%$ & $11 \%$ & $3 \%$ & $5 \%$ & $4 \%$ & $0 \%$ & $3 \%$ \\
\hline $\begin{array}{l}\text { Sibutramine } \\
(N=100)\end{array}$ & $65 \%$ & $9 \%$ & $4 \%$ & $11 \%$ & $1 \%$ & $4 \%$ & $1 \%$ & $4 \%$ & $1 \%$ \\
\hline $\begin{array}{l}\text { Orlistat } \\
(N=100)\end{array}$ & $78 \%$ & $6 \%$ & $5 \%$ & $7 \%$ & $0 \%$ & $0 \%$ & $2 \%$ & $0 \%$ & $2 \%$ \\
\hline
\end{tabular}

by the average general practitioner, especially if the treatment is new on the market. Unbiased continued medical education about new drugs appears to be important, and electronic tools for prospective data collection could possibly improve the quality regarding both initiation of therapy and followup of particularly sensitive and/or expensive drug treatments. These results show the importance of prioritizing the development of such assistance.

\section{Conclusions}

In conclusion, this observational study suggests that the treatment with weight-loss drugs was of limited clinical benefit the way they were used in a large proportion of Swedish primary care. Also, our results indicate that effective models are needed to evaluate the risks and benefits of treatment with life-style drugs in the everyday clinical setting.

\section{Conflict of Interests}

The authors declare that they have no conflict of interest.

\section{Acknowledgment}

We gratefully acknowledge Anders Sundström, Ph.D. at the Centre for Pharmacoepidemiology, Karolinska Institutet for valuable statistical advice.

\section{References}

[1] D. W. Haslam and W. P. T. James, “Obesity,” Lancet, vol. 366, no. 9492, pp. 1197-1209, 2005.

[2] World Health Organization (WHO). Obesity and overweight. Fact sheet No 311, 2010, http://www.who.int/mediacentre/ factsheets/fs311/en/index.html.

[3] M. Neovius, A. Janson, and S. Rössner, "Prevalence of obesity in Sweden," Obesity Reviews, vol. 7, no. 1, pp. 1-3, 2006.

[4] G. A. Bray, Contemporary Diagnosis and Management of Obesity and the Methabolic Syndrome, Handbooks in Health Care, Newtown, Pa, USA, 3rd edition, 2003.

[5] "Questions and answers on the recommendation to suspend the marketing authorisation of Acomplia (rimonabant)," EMEA, 2008, http://www.ema.europa.eu/humandocs/ PDFs/EPAR/acomplia/53715308en.pdf.

[6] "European medicines agency recommends suspension of marketing authorisation for sibutramine," EMEA, 2010, http://www.ema.europa.eu/ema/index.jsp?curl=pages/news_ and_events/news/2010/01/news_detail_000985.jsp.
[7] "Lorcaserin hydrochloride APD-356 for obesity or overweight people with at least one co-morbidity," National Horizon Scanning Centre, University of Birmingham, 2008, http://www.haps.bham.ac.uk/publichealth/horizon/outputs/ documents/2008/may-august/Lorcaserin_hydrochloride_. APD-356_.pdfk.

[8] A. Astrup, S. Madsbad, L. Breum, T. J. Jensen, J. P. Kroustrup, and T. M. Larsen, "Effect of tesofensine on bodyweight loss, body composition, and quality of life in obese patients: a randomised, double-blind, placebo-controlled trial," The Lancet, vol. 372, no. 9653, pp. 1906-1913, 2008.

[9] B. Wettermark, M. E. Persson, N. Wilking et al., "Forecasting drug utilization and expenditure in a metropolitan health region," BMC Health Services Research, vol. 10, p. 128, 2010.

[10] B. Wettermark, P. Raaschou, T. Forslund, and P. Hjemdahl, "Fortsatta frågetecken kring bantningsmedlet rimonabant," Läkartidningen, vol. 104, no. 51-52, pp. 3879-3881, 2007.

[11] "Summary of product characteristics, Acomplia," EMEA, 2010, http://www.ema.europa.eu/docs/en_GB/document_library/EPAR_-_Product_Information/human/000666/WC500021287.pdf.

[12] D. Rucker, R. Padwal, S. K. Li, C. Curioni, and D. C. W. Lau, "Long term pharmacotherapy for obesity and overweight: updated meta-analysis," The British Medical Journal, vol. 335, no. 7631, pp. 1194-1199, 2007.

[13] "Summary of product characteristics, Xenical," eMC, 2011, http://www.medicines.org.uk/emc/document.aspx?documentid=1746.

[14] "Summary of product characteristics, Reductil," eMC, 2010, http://www.medicines.org.uk/emc/medicine/14056/SPC.

[15] P. Engfeldt, C. Popa, P. Bergensand et al., "Kvalitetsarbete kring läkemedelsförskrivning i primärvården. Nytt databasprogram underlättar uppföljning av läkemedelsbehandling," Läkartidningen, vol. 98, no. 50, pp. 5767-5771, 2001.

[16] C. Norman, R. Zarrinkoub, J. Hasselström, B. Godman, F. Granath, and B. Wettermark, "Potential savings without compromising the quality of care," International Journal of Clinical Practice, vol. 63, no. 9, pp. 1320-1326, 2009.

[17] B. Wettermark, N. Hammar, C. M. Fored et al., "The new swedish prescribed drug register-opportunities for pharmacoepidemiological research and experience from the first six months," Pharmacoepidemiology and Drug Safety, vol. 16, no. 7, pp. 726-735, 2007.

[18] P. A. Caetano, J. M. C. Lam, and S. G. Morgan, "Toward a standard definition and measurement of persistence with drug therapy: examples from research on statin and antihypertensive utilization," Clinical Therapeutics, vol. 28, no. 9, pp. 1411-1424, 2006.

[19] A. Mason, "New medicines in primary care: a review of influences on general practitioner prescribing," Journal of Clinical Pharmacy and Therapeutics, vol. 33, no. 1, pp. 1-10, 2008. 
[20] M. R. Law, S. R. Majumdar, and S. B. Soumerai, "Effect of illicit direct to consumer advertising on use of etanercept, mometasone, and tegaserod in Canada: controlled longitudinal study," The British Medical Journal, vol. 337, p. a1055, 2008.

[21] S. Gilbody, P. Wilson, and I. Watt, "Benefits and harms of direct to consumer advertising: a systematic review," Quality and Safety in Health Care, vol. 14, no. 4, pp. 246-250, 2005.

[22] R. Padwal, A. Kezouh, M. Levine, and M. Etminan, "Longterm persistence with orlistat and sibutramine in a population-based cohort," The International Journal of Obesity, vol. 31, no. 10, pp. 1567-1570, 2007.

[23] K. Johansson, K. Neovius, S. M. Desantis, S. Rössner, and M. Neovius, "Discontinuation due to adverse events in randomized trials of orlistat, sibutramine and rimonabant: a metaanalysis," Obesity Reviews, vol. 10, no. 5, pp. 564-575, 2009.

[24] J. P. Després, A. Golay, L. Sjöström, and Rimonabant in Obesity-Lipids Study Group, "Effects of rimonabant on metabolic risk factors in overweight patients with dyslipidemia," The New England Journal of Medicine, vol. 353, no. 20, pp. 2121-2134, 2005.

[25] L. F. Van Gaal, A. M. Rissanen, A. J. Scheen, O. Ziegler, and S. Rössner, "Effects of the cannabinoid-1 receptor blocker rimonabant on weight reduction and cardiovascular risk factors in overweight patients: 1-Year experience from the RIOEurope study," Lancet, vol. 365, no. 9468, pp. 1389-1397, 2005.

[26] A. J. Scheen, N. Finer, P. Hollander, M. D. Jensen, and L. F. Van Gaal, "Efficacy and tolerability of rimonabant in overweight or obese patients with type 2 diabetes: a randomised controlled study," Lancet, vol. 368, no. 9548, pp. 1660-1672, 2006.

[27] F. X. Pi-Sunyer, L. J. Aronne, H. M. Heshmati, J. Devin, and J. Rosenstock, "Effect of rimonabant, a cannabinoid-1 receptor blocker, on weight and cardiometabolic risk factors in overweight or obese patients: RIO-North America: a randomized controlled trial," The Journal of the American Medical Association, vol. 368, no. 9548, pp. 1660-1672, 2006. 


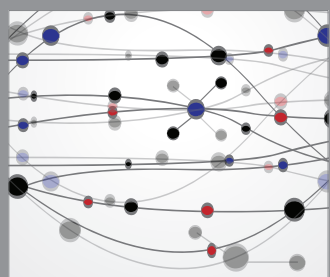

The Scientific World Journal
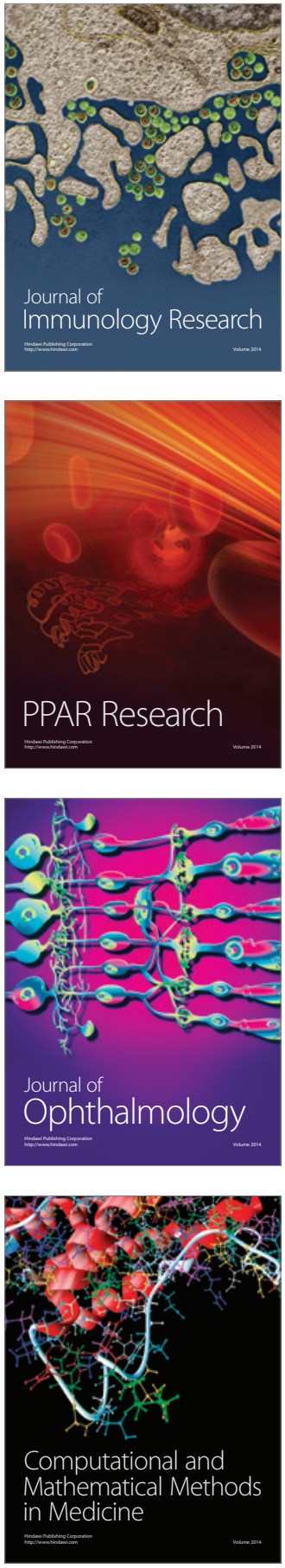

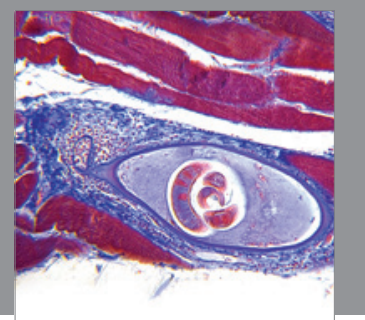

Gastroenterology

Research and Practice
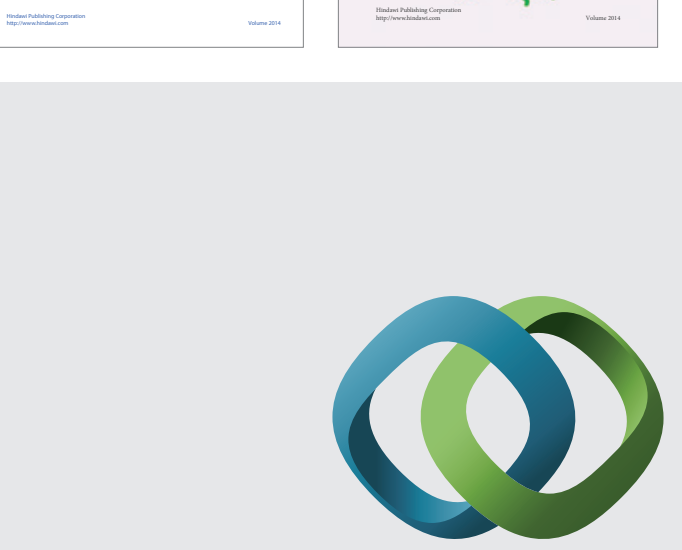

\section{Hindawi}

Submit your manuscripts at

http://www.hindawi.com
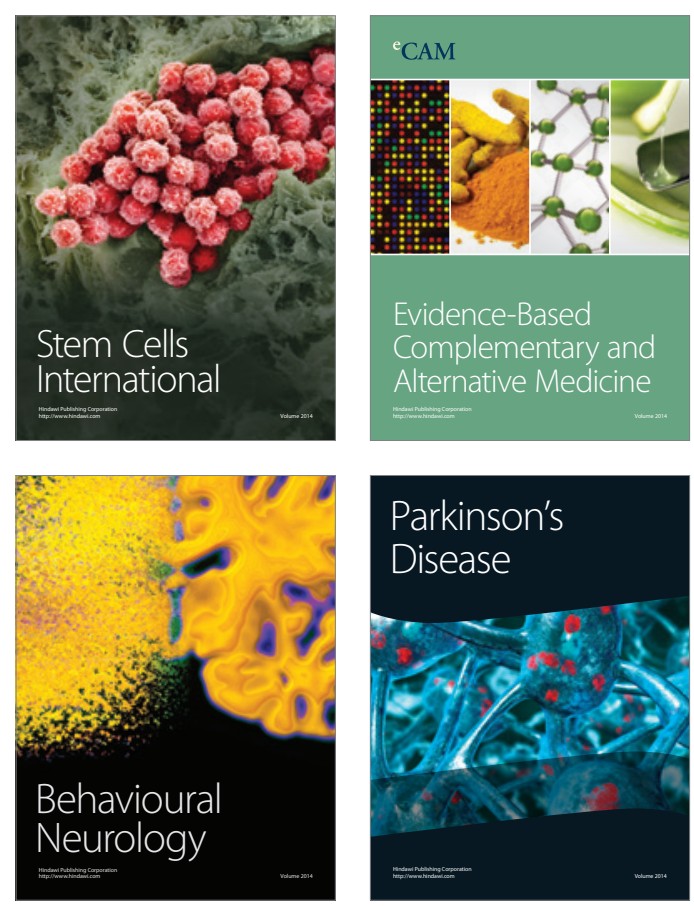

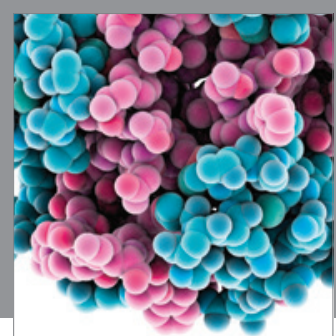

Journal of
Diabetes Research

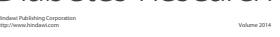

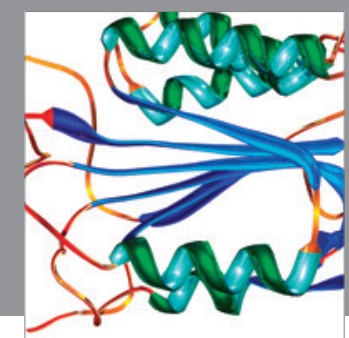

Disease Markers
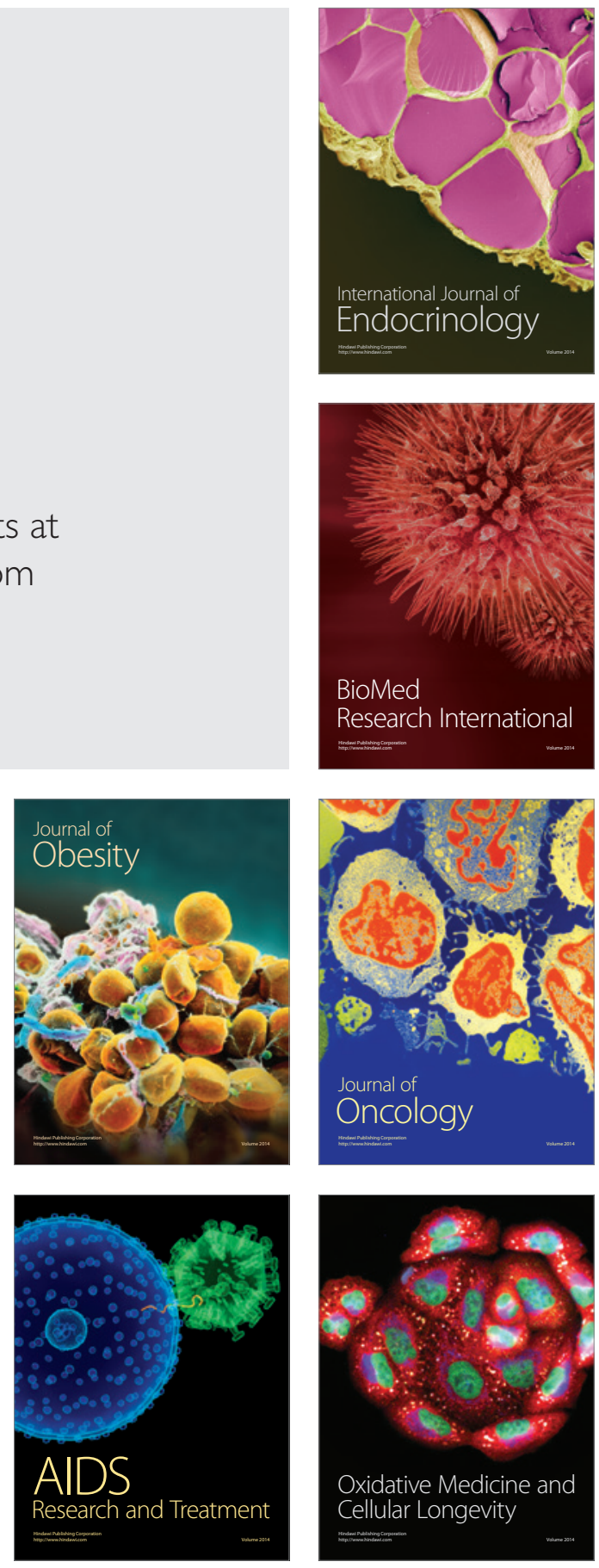